\title{
Rare earth elements activate the secondary metabolite-biosynthetic gene clusters in Streptomyces coelicolor A3(2)
}

\author{
Yukinori Tanaka ${ }^{1,2}$, Takeshi Hosaka ${ }^{3}$ and Kozo Ochi ${ }^{1,4}$ \\ Genome sequencing projects have revealed many biosynthesis gene clusters for the production of as-yet unknown secondary \\ metabolites, especially in actinomycetes. Here, we report that the rare earth elements, scandium and/or lanthanum, markedly \\ activate, ranging from 2.5- to 12-fold, the expression of nine genes belonging to nine secondary metabolite-biosynthetic gene \\ clusters of Streptomyces coelicolor A3(2) when added to the medium at low concentrations. HPLC analysis of ethyl acetate- \\ extractable metabolites indicated the detectability of several compounds only in the rare earth-treated cultures. This approach \\ should facilitate discovery of new biologically active compounds and the study of secondary metabolite production.
}

The Journal of Antibiotics (2010) 63, 477-481; doi:10.1038/ja.2010.53; published online 16 June 2010

Keywords: lanthanum; rare earth; scandium; silent genes; Streptomyces coelicolor

\section{INTRODUCTION}

Actinomycetes produce a variety of natural products that are of major importance in the pharmaceutical industry. More than $50 \%$ of all antiinfective and anticancer compounds developed over the past 25 years have been natural products or derivatives of such products. ${ }^{1}$ There is accumulating evidence that the ability of actinomycetes to produce antibiotics and other bioactive secondary metabolites has been underestimated due to the presence of cryptic gene clusters. That is, genome sequencing projects have revealed many biosynthetic gene clusters for the production of unknown secondary metabolites. For example, Streptomyces coelicolor, S. avermitilis, S. griseus and Saccharopolyspora erythraea are each known to produce 3-5 secondary metabolites but actually possess $>20$ clusters that encode known or predicted biosynthetic pathways for secondary metabolites. ${ }^{2-5}$ Exploitation of such genetic potential in actinomycetes may therefore lead to the isolation of new biologically active compounds. ${ }^{6}$ Our laboratory has previously developed a method to increase antibacterial production. ${ }^{7-9}$ This new approach, called 'ribosome engineering, ${ }^{10,11}$ has several advantages. In this method, bacteria are grown on antibiotics to select antibioticresistant strains. Strains with mutations in the $r p s L$ gene (encoding the ribosomal protein S12) or $r p o B$ gene (encoding the RNA polymerase $\beta$-subunit) are isolated using streptomycin and rifampicin, respectively. These studies showed that mutations in ribosomal proteins and/ or RNA polymerase alter bacterial gene expression, eventually leading to the discovery of novel antibiotics. ${ }^{12}$ More recently, during the course of studying the effects of rare earth elements on bacterial physiology, we found that rare earths can elicit bacterial capabilities, and thus exert marked effects on secondary metabolism in streptomycetes, the typical soil microorganisms that often produce antibiotics. ${ }^{13}$

Rare earth is a general term for 17 elements that include scandium (Sc), yttrium $(\mathrm{Y})$ and the lanthanides (15 elements from lanthanum (La) to lutetium $(\mathrm{Lu})$ ). Of the 17 elements, promethium $(\mathrm{Pm})$ scarcely exists in universe as a radioisotope. Rare earth elements have been widely used in high-technology products, such as permanent magnets, fluorescent materials and new ceramics, and they are currently being used in computers, mobile telephones, plasma displays, magneto-optical disks, high-powered lasers, fluorescent lamps and hybrid cars. ${ }^{14}$ Despite their importance in physics and chemistry, the significance of rare earths in biology has largely been overlooked. Working with S. coelicolor A3(2), the genetically best-characterized strain of Streptomyces, we report here that both scandium and lanthanum activate many secondary metabolite-biosynthetic genes, the majority of which may represent 'silent' or 'poorly expressed' genes in this organism.

\section{MATERIALS AND METHODS}

Bacterial strains and culture conditions

S. coelicolor A3(2) strain 1147, a prototrophic wild-type strain, which produces actinorhodin, ${ }^{15}$ was used in this study. Cultivation was performed at $30^{\circ} \mathrm{C}$. GYM medium was described previously. ${ }^{16}$ Scandium chloride hexahydrate $\left(\mathrm{ScCl}_{3} \cdot 6 \mathrm{H}_{2} \mathrm{O}\right.$; purity, $\left.99.9 \%\right)$ and lanthanum chloride heptahydrate

\footnotetext{
${ }^{1}$ National Food Research Institute, Tsukuba, Ibaraki, Japan; ${ }^{2}$ Department of Applied Biological Chemistry, Faculty of Agriculture, Shizuoka University, Shizuoka, Japan; ${ }^{3}$ International Young Researchers Empowerment Center, Shinshu University, Nagano, Japan and ${ }^{4}$ Hiroshima Institute of Technology, Department of Health Science, Faculty of Applied Information Science, Hiroshima, Japan

Correspondence: Dr K Ochi, Hiroshima Institute of Technology, Department of Health Science, Faculty of Applied Information Science, Miyake 2-1-1, Saeki-ku, Hiroshima 731-5193, Japan.

E-mail: k.ochi.bz@it-hiroshima.ac.jp
}

Received 2 March 2010; revised 12 March 2010; accepted 15 March 2010; published online 16 June 2010 
$\left(\mathrm{LaCl}_{3} \cdot 7 \mathrm{H}_{2} \mathrm{O}\right.$; purity, $\left.99.9 \%\right)$, together with other rare earths (all chloride-salts; purity, $>97 \%$ ) were purchased from Wako Pure Chemical (Osaka, Japan). These rare earths were added to the autoclaved agar medium after cooling to $50-60{ }^{\circ} \mathrm{C}$.

\section{Transcriptional analysis by real-time quantitative PCR}

Total RNAs were purified from cells grown on GYM plates covered with cellophane for the indicated times using Isogen reagent (Nippon Gene, Toyama, Japan) according to the manufacturer's protocol. After treatment with RNasefree DNase I (amplification grade; Invitrogen, Carlsbad, CA, USA), $1 \mu \mathrm{g}$ of each of the total RNAs was used as a template for reverse transcription $(20 \mu \mathrm{l})$ with a high-capacity RNA-to-cDNA Kit (Applied Biosystems, Foster City, CA, USA). The samples were diluted with an appropriate volume of water and analyzed using the 7300 real-time quantitative PCR (qPCR) system and THUNDERBIRD qPCR Mix (Toyobo, Osaka, Japan). Each transcriptional assay was normalized to the corresponding transcriptional level of the $h r d B$ gene encoding the principal sigma factor. Primers used for real-time $\mathrm{qPCR}$ are listed in Table 1. All reactions were performed under the following conditions: $1 \mathrm{~min}$ at $95^{\circ} \mathrm{C}$, followed by 40 cycles of $15 \mathrm{~s}$ at $95^{\circ} \mathrm{C}$ for denaturation and $40 \mathrm{~s}$ at $60{ }^{\circ} \mathrm{C}$ for annealing and extension.

\section{Table 1 Primers used for real-time PCR}

\begin{tabular}{|c|c|c|}
\hline Gene & Primer & Oligonucleotide sequence $\left(5^{\prime} \rightarrow 3^{\prime}\right)$ \\
\hline \multirow[t]{2}{*}{$h r d B$} & hrdB-F918 & GGGCAACCTCGGTCTGATC \\
\hline & hrdB-R980 & GAGAACTTGTAGCCCTTGGTGTAGT \\
\hline \multirow[t]{2}{*}{ SCO0124 } & SC00124-F1132 & GAGGACCCGTCGGCATTG \\
\hline & SC00124-R1195 & GGGTGAGGTAGGCCGTGAT \\
\hline \multirow[t]{2}{*}{ Sc00381 } & SC00381-F1280 & GCCCGGACATCCGAAGAC \\
\hline & SC00381-R1351 & CGCTGCGTCCGCTGATCT \\
\hline \multirow[t]{2}{*}{ Sc00489 } & SC00489-F3 & GAGCACCAACCCCTTCGA \\
\hline & SC00489-R66 & CTGGCCCTCGTCGTTCAC \\
\hline \multirow[t]{2}{*}{ SC01207 } & SC01207-F495 & CACCGACCGGCACTCCAT \\
\hline & SC01207-R601 & CCGAGAAGTAGGCGTTCATCTC \\
\hline \multirow[t]{2}{*}{ SC01268 } & SC01268-F544 & GTCGGACAGGCGGAGGAA \\
\hline & Sc01268-R609 & GGGCAGGGAGACGAAACTG \\
\hline \multirow[t]{2}{*}{ SCO2785 } & SC02785-F819 & CCTGGCCCAGCAGTCCAT \\
\hline & SC02785-R889 & GGGCAGTCTTCACGTAGTGCTT \\
\hline \multirow[t]{2}{*}{ Sc03215 } & SC03215-F303 & CGGACTGGTGCGCAAGGT \\
\hline & SC03215-R364 & CGCAGGTGAGGATGTTGAAGT \\
\hline Sc05085 & actII-ORF4-F17 & TGGGACGTGTCCATGTAATCA \\
\hline (actlI-ORF4) & actII-ORF4-R76 & CCTTCGAGGATTTAAGCGGAAT \\
\hline \multirow[t]{2}{*}{ Sc05223 } & SC05223-F814 & CTCACCCCGGGCAGTGAA \\
\hline & Sc05223-R866 & GCCTGGAGCAACCACATGA \\
\hline \multirow[t]{2}{*}{ Sc05800 } & Sc05800-F1651 & GACGAGCGCTTCGCCTACTA \\
\hline & SC05800-R1705 & TGCCGATGAGACCGAACA \\
\hline Sc05877 & redD-F201 & CGGACCCAGCCTGTACAACT \\
\hline$(r e d D)$ & redD-R265 & CGATCGATACGGGTCCCAAT \\
\hline \multirow[t]{2}{*}{ SC06283 } & SC06283-F312 & CACGAGCGAGGCCTTCCT \\
\hline & Sc06283-R406 & CGAAGTTCTGCGCGAACCA \\
\hline \multirow[t]{2}{*}{ Sc06430 } & SC06430-F458 & TGCAGTCCACCCAGATGTTC \\
\hline & SC06430-R579 & CCAGACGGTGACCACGTACA \\
\hline \multirow[t]{2}{*}{ Sc06766 } & Sc06766-F35 & CTACATACCTGGCCGAACAGAAG \\
\hline & SC06766-R91 & CCACGATGAGCGGGAACT \\
\hline \multirow[t]{2}{*}{ Sc06826 } & SC06826-F772 & AGGGTCTGCCACGTGTTCA \\
\hline & SC06826-R827 & GGGTCGAGGATGACCTTCAG \\
\hline \multirow[t]{2}{*}{ Sc07670 } & SC07670-F278 & TCGGGCCCTACTGGAACAC \\
\hline & SC07670-R382 & CCACGACCGCGAGGTAGTT \\
\hline \multirow[t]{2}{*}{ SC07684 } & SC07684-F629 & ACACCGAACACCGGTCCTT \\
\hline & SC07684-R748 & CGGGATGGACGTTGTACCA \\
\hline
\end{tabular}

\section{HPLC analysis of culture extracts}

Spores and hyphal fragments of $S$. coelicolor 1147 were inoculated onto GYM agar medium $(25 \mathrm{ml}$ per culture plate $(\phi 90 \times 15 \mathrm{~mm}))$ with or without scandium $(200 \mu \mathrm{M})$ or lanthanum $(1900 \mu \mathrm{M})$ and then incubated at $30^{\circ} \mathrm{C}$ for 3 or 5 days. The agar medium with cells (from two plates) was extracted twice with $50 \mathrm{ml}$ of EtOAc by gently agitating for $6 \mathrm{~h}$. The EtOAc layer was collected and evaporated to dryness. The dried crude extract was dissolved in $5 \mathrm{ml}$ of $50 \%$ aqueous $\mathrm{MeOH}$, filtered through Cosmonice filter $\mathrm{W}$ (pore size, $0.45 \mu \mathrm{m}$; Millipore, Billerica, MA, USA), and subjected to HPLC. The HPLC apparatus consisted of a Shimadzu Prominence HPLC system equipped with diode array detector SPD-M20A (Shimadzu, Kyoto, Japan). Aliquots of $200 \mu \mathrm{l}$ of each sample were loaded onto a column (CAPCELL PAK C18 MG II, 4.6×250 mm, $5 \mu \mathrm{m}$ particle size; Shiseido, Tokyo, Japan) with a precolumn (CAPCELL PAK C18 MG II, $4.6 \times 10 \mathrm{~mm}, 5 \mu \mathrm{m}$ particle size; Shiseido) and eluted at a flow rate of $1 \mathrm{ml} \mathrm{min}^{-1}$. Solvents and conditions used were as follows: $0-5 \mathrm{~min}, 40 \%$ $\mathrm{CH}_{3} \mathrm{CN}$ containing $0.05 \%$ TFA; 5-40 min; a linear gradient from 40 to $100 \%$ $\mathrm{CH}_{3} \mathrm{CN}$ containing $0.05 \%$ TFA; $40-50 \mathrm{~min} ; 100 \% \mathrm{CH}_{3} \mathrm{CN}$ containing $0.05 \%$

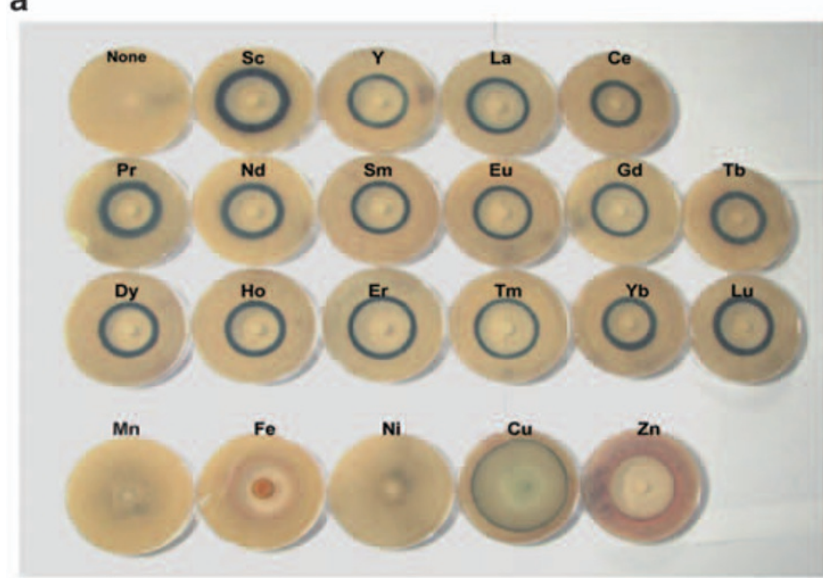

b
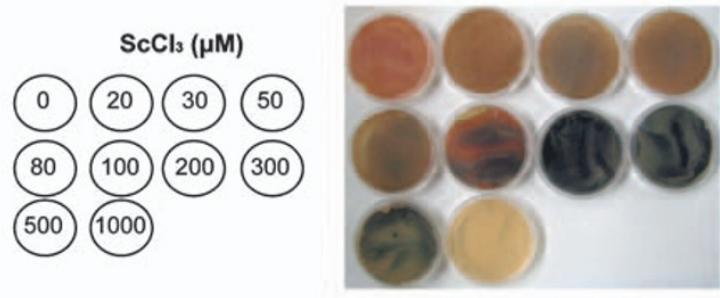

C


Figure 1 Effects of exogenously added rare earths on actinorhodin production. (a) S. coelicolor wild-type strain 1147 was spread on GYM agar, and a paper disk containing $4 \mathrm{mg}$ of each rare earth (all chloride salts) was placed in the center of the plate. The plates were incubated at $30^{\circ} \mathrm{C}$ for 4 days. Blue represents the antibiotic actinorhodin, whereas the clear zone of the center represents growth inhibition. (b, c) S. coelicolor 1147 was spread on GYM agar containing various amounts of scandium or lanthanum, followed by incubation for 4 days. Complete growth inhibition was detected at $1200 \mu \mathrm{m}$ scandium and $5000 \mu \mathrm{m}$ lanthanum. 
TFA. Multiple wavelength monitoring was performed at 215, 254, 320, 450, 530 and $640 \mathrm{~nm}$.

\section{RESULTS AND DISCUSSION}

Rare earths enhance actinorhodin production by $S$. coelicolor Previously, we showed that several rare earths, including scandium and lanthanum, activate actinorhodin production in S. coelicolor and S. lividans when added to solid or liquid medium. ${ }^{13}$ Therefore, we first examined the efficacy of all (except for promethium $(\mathrm{Pm})$ ) rare earths_-scandium $(\mathrm{Sc})$, yttrium $(\mathrm{Y})$, lanthanum $(\mathrm{La})$, cerium $(\mathrm{Ce})$, praseodymium $(\mathrm{Pr})$, neodymium $(\mathrm{Nd})$, samarium $(\mathrm{Sm})$, europium $(\mathrm{Eu})$, gadolinium $(\mathrm{Gd})$, terbium $(\mathrm{Tb})$, dysprosium (Dy), holmium (Ho), erbium (Er), thulium (Tm), ytterbium $(\mathrm{Yb})$ and lutetium $(\mathrm{Lu})$ (all chloride salts)—in enhancing actinorhodin production by S. coelicolor. As shown in Figure 1a, these rare earths were all effective in enhancing actinorhodin production, and the effect of scandium was most pronounced. In contrast, manganese $(\mathrm{Mn})$, iron $(\mathrm{Fe})$, nickel (Ni), copper $(\mathrm{Cu})$ and zinc $(\mathrm{Zn})$ (all chloride salts) were not effective. Scandium was effective at concentrations of $100-500 \mu \mathrm{M}$, with the optimal concentration of $200 \mu \mathrm{M}$, determined using plates containing fixed concentrations of scandium (Figure 1b). Conversely, lanthanum was effective over a limited concentration range of $1700-2500 \mu \mathrm{M}$, with the optimal concentration of $1900 \mu \mathrm{M}$ (Figure 1c).

Effects of scandium and lanthanum on transcription of secondary metabolite-biosynthetic gene clusters

A recent study in our laboratory indicated that certain mutations in $r p o B$ (encoding RNA polymerase $\beta$-subunit) or $r p s L$ genes can activate 'silent' genes of actinomycetes or Bacillus subtilis, leading to the discovery of novel antibacterial agents. ${ }^{12,17}$ The activation of silent genes by generating $r p o B \mathrm{H} 437 \mathrm{D}$ or $r p o B \mathrm{H} 437 \mathrm{~L}$ mutations in Streptomyces sp. 631689 was attributed, at least in part, to the increased affinity of the mutant RNA polymerase for promoters. Later, we found that $r s m G$ mutations, which confer a low level of resistance to streptomycin, can activate not only streptomycin production but also the expression of other secondary metabolitebiosynthetic genes in $S$. griseus, although the effects were not dramatic. ${ }^{18}$ Therefore, our next interest was to study the effects of rare earths on the expression of secondary metabolite-biosynthetic gene clusters present in the $S$. coelicolor wild-type strain. A total of 17 genes belonging to 17 secondary metabolite-biosynthetic gene clusters (Table 2) were subjected to transcriptional analysis by real-time qPCR, using the cells grown with the optimal concentrations of scandium and lanthanum (200 and $1900 \mu \mathrm{M}$, respectively). Analysis of cells harvested at late growth phase $(36,48$ and $60 \mathrm{~h})$ indicated that scandium and lanthanum both markedly activated not only the actinorhodin biosynthetic gene cluster (as represented by actIIORF4) but also the expression of other secondary metabolite-biosynthetic genes (Figure 2). The profiles of changes in expression of genes belonging to each secondary metabolite-biosynthetic gene cluster are shown in Supplementary Figure S1. Marked enhancement of expression was observed in actII-ORF4 (12-fold), SCO0489 (4-fold),

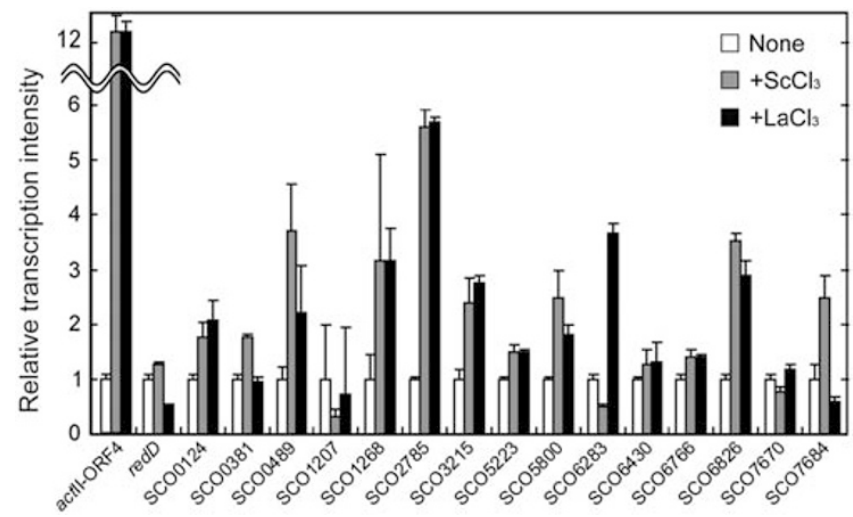

Figure 2 Transcriptional analysis of the genes involved in the secondary metabolite-biosynthetic gene clusters. The RNAs were extracted from cells grown to late growth phase $(36,48$ and $60 \mathrm{~h})$. Total RNA preparation and real-time qPCR was performed as described in Materials and methods section. The maximum expression levels were compared, taking the maximum expression levels of control (no addition of rare earths) as unity $(=1)$.

Table 2 Genes of $S$. coelicolor 1147 analyzed in this study

\begin{tabular}{|c|c|c|c|}
\hline$G_{e n e^{a}}$ & Product & Secondary metabolite-biosynthetic gene cluster ${ }^{b}$ & Reference \\
\hline SCO0124 & Hypothetical protein & Eicosapentaenoic acid (type I iterative PKS, SC00124-0129) & Bentley et $a .^{2}$ \\
\hline Sc00381 & Putative glycosyl transferase & Unknown (deoxysugar, Sc00381-0401) & \\
\hline Sc00489 & Conserved hypothetical protein & Coelichelin (NRPS, SC00489-0499) & Lautru et al. ${ }^{19}$ \\
\hline SC01207 & Putative cytochrome P450 & Tetrahydroxynaphthalene (type III PKS, SC01206-1208) & Bentley et al. ${ }^{2}$ \\
\hline SC01268 & Putative acyltransferase & Unknown (type II fatty acid synthase, SC01265-1273) & \\
\hline SCO2785 & Conserved hypothetical protein & Desferrioxamines (siderophore synthetase, SCO2782-2785) & Bentley et $a .^{2}$ \\
\hline $\operatorname{sc03215}$ & Hypothetical protein & CDA (NRPS, SC03210-3249) & Bentley et al. ${ }^{2}$ \\
\hline SC05085 (actlI-ORF4) & Actinorhodin cluster activator protein & Actinorhodin (type II PKS, SC05071-5092) & Bentley et $a .^{2}$ \\
\hline SC05223 & Putative cytochrome P450 & Unknown (sesquiterpene synthase, SC05222-5223) & \\
\hline SC05800 & Conserved hypothetical protein & Unknown (siderophore synthetase, SC05799-5801) & \\
\hline SC05877 (redD) & Transcriptional regulator RedD & Prodiginines (NRPS; type I modular PKS, SC05877-5898) & Bentley et $a .^{2}$ \\
\hline SC06283 & Conserved hypothetical protein & Unknown (type I modular PKS, SC06273-6288) & \\
\hline SC06430 & Hypothetical protein & Unknown (NRPS, SC06429-6438) & \\
\hline SC06766 & Conserved hypothetical protein & Hopanoids (squalene-Hopene cyclase, Sc06759-6771) & Bentley et al. ${ }^{2}$ \\
\hline SC06826 & Conserved hypothetical protein & Unknown (type I modular PKS, SC06826-6827) & \\
\hline Sc07670 & Conserved hypothetical protein & Unknown (type III PKS, SC07669-7671) & \\
\hline Sc07684 & Conserved hypothetical protein & Coelibactin (NRPS, SC07681-7691) & Bentley et al. ${ }^{2}$ \\
\hline
\end{tabular}

Abbreviation: CDA, calcium-dependent antibiotic

${ }^{\mathrm{a}} \mathrm{Gene}$ names are from Bentley et $a l^{2}{ }^{2}$

bobtained from Challis and Hopwood. 20 

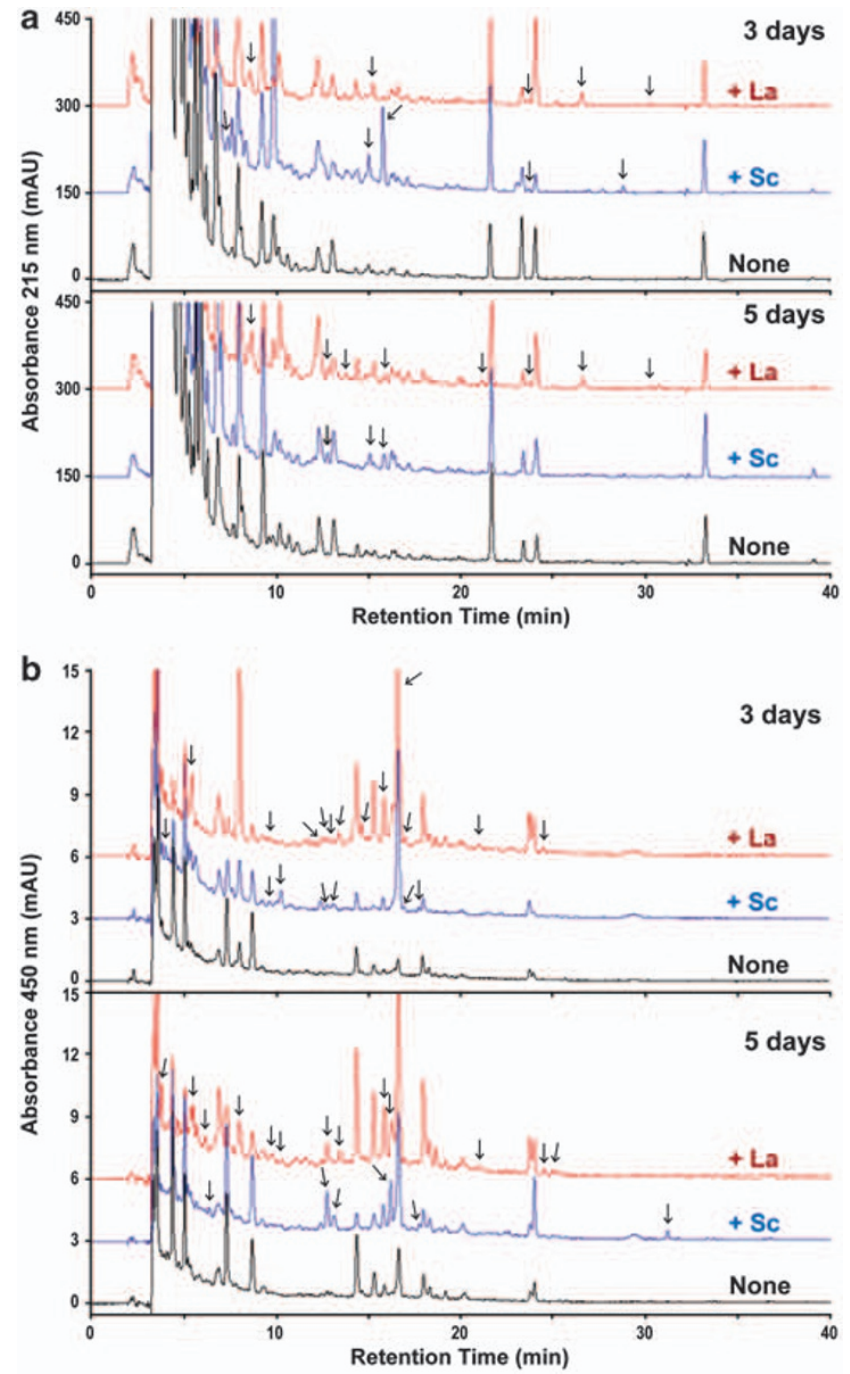

Figure 3 Comparative metabolic profiling of the culture extracts. S. coelicolor 1147 was grown on GYM agar medium in the presence or absence of scandium or lanthanum. The culture extracts with EtOAc were prepared after 3 or 5 days of incubation and analyzed by HPLC. The absorbance of the eluate was monitored at $215 \mathrm{~nm}$ (a) and $450 \mathrm{~nm}$ (b). The arrows indicate the peaks that were scarcely detected in the control (no addition of rare earths).

SCO1268 (3-fold), SCO2785 (6-fold), SCO3215 (3-fold), SCO5800 (2.5-fold), SCO6283 (4-fold), SCO6826 (3.5-fold) and SCO7684 (2.5-fold). It is notable that, among these genes, SCO1268, SCO5800, SCO6283 and SCO6826 belong to gene clusters, metabolic products of which have not yet been identified (Table 2).

\section{HPLC profile of culture extract}

We next compared the metabolic profile of the culture by analyzing the EtOAc-extractable metabolites by HPLC monitoring at different wavelengths (215 and $450 \mathrm{~nm}$ ). Several peaks (indicated by arrows in Figure 3) were detected only when the strain 1147 was grown in the presence of scandium $(200 \mu \mathrm{M})$ or lanthanum $(1900 \mu \mathrm{M})$. Although each peak detected in the presence of rare earths was not identified in this study, the appearance of these peaks reflects the markedly enhanced expression of secondary metabolite-biosynthetic genes (see Figure 2).

\section{CONCLUSION}

Antibiotic biosynthesis in streptomycetes is a developmentally regulated process, with production associated with the stationary phase. ${ }^{11,21}$ We showed that scandium and lanthanum are both effective not only for enhancement of actinorhodin production but also for activation of silent or poorly expressed genes in S. coelicolor. In particular, scandium appears to be a feasible reagent for gene activation because it showed a rather wide range of effective concentrations. Another advantage of using rare earths is that this method does not require any gene engineering technology or genomic information for the strains examined. As rare earths are distributed ubiquitously throughout the world, it is conceivable that microorganisms have acquired the ability to respond to low levels of these elements over the course of their long evolutionary history, possibly as a means of adapting their physiology to the prevailing conditions. The compelling effect of low levels of scandium on antibiotic production implies that scandium functions in situ as a factor that induces or stimulates the production of secondary metabolites, which can include pigments, mycotoxins, phytotoxins and antibiotics. The mechanism of action, however, remains to be clarified. The present method, together with other methods reported recently, ${ }^{8,9,12,22-24}$ may be useful for activating silent genes, eventually leading to the discovery of novel biologically active compounds.

\section{CONFLICT OF INTEREST}

The authors declare no conflict of interest.

\section{ACKNOWLEDGEMENTS}

This paper is dedicated to Professor Arnold L Demain for celebrating his 60 years of scientific career. This work was supported by grants to KO (Effective Promotion of Joint Research of Special Coordination Funds) from the Ministry of Education, Culture, Sports and Technology of the Japanese Government.

1 Newman, D. J. \& Cragg, G. M. Natural products as sources of new drugs over the last 25 years. J. Nat. Prod. 70, 461-477 (2007).

2 Bentley, S. D. et al. Complete genome sequence of the model actinomycete Streptomyces coelicolor A3(2). Nature 417, 141-147 (2002).

3 Ikeda, H. et al. Complete genome sequence and comparative analysis of the industrial microorganism Streptomyces avermitilis. Nat. Biotechnol. 21, 526-531 (2003).

4 Ohnishi, Y. et al. Genome sequence of the streptomycin-producing microorganism Streptomyces griseus IFO 13350. J. Bacteriol. 190, 4050-4060 (2008).

5 Oliynyk, M. et al. Complete genome sequence of the erythromycin-producing bacterium Saccharopolyspora erythraea NRRL23338. Nat. Biotechnol. 25, 447-453 (2007).

6 Clardy, J., Fischbach, M. A. \& Walsh, C. T. New antibiotics from bacterial natural products. Nat. Biotechnol. 24, 1541-1550 (2006).

$7 \mathrm{Hu}, \mathrm{H}$., Zang, Q. \& Ochi, K. Activation of antibiotic biosynthesis by specific mutations in the $r p o B$ gene (encoding the RNA polymerase $\beta$ subunit) of Streptomyces lividans. J. Bacteriol. 184, 3984-3991 (2002).

8 Wang, G., Hosaka, T. \& Ochi, K. Dramatic activation of antibiotic production in Streptomyces coelicolor by cumulative drug resistance mutations. Appl. Environ. Microbiol. 74, 2834-2840 (2008).

9 Tanaka, Y. et al. Antibiotic overproduction by rpsL and rsmG mutants of various actinomycetes. Appl. Environ. Microbiol. 75, 4919-4922 (2009).

10 Ochi, K. et al. Ribosome engineering and secondary metabolite production. Adv. Appl. Microbiol. 56, 155-184 (2004).

11 Ochi, K. From microbial differentiation to ribosome engineering. Biosci. Biotechnol. Biochem. 71, 1373-1386 (2007).

12 Hosaka, T. et al. Antibacterial discovery in actinomycetes strains with mutations in RNA polymerase or ribosomal protein S12. Nat. Biotechnol. 27, 462-464 (2009).

13 Kawai, K., Wang, G., Okamoto, S. \& Ochi, K. The rare earth, scandium, causes antibiotic overproduction in Streptomyces spp. FEMS Microbiol. Lett. 274, 311-315 (2007).

14 Bunzli, J.-C. G. \& Choppin, G. R. Lanthanide Probes in Life, Chemical and Earth Sciences (Elsevier, Amsterdam, 1989).

15 Kieser, T., Bibb, M. J., Buttner, M. J., Chater, K. F. \& Hopwood, D. A. Practical Streptomyces Genetics (The John Innes Foudation, Norwich, UK, 2000). 
16 Ochi, K. Metabolic initiation of differentiation and secondary metabolism by Streptomyces griseus: significance of the stringent response (ppGpp) and GTP content in relation to A factor. J. Bacteriol. 169, 3608-3616 (1987).

17 Inaoka, T., Takahashi, K., Yada, H., Yoshida, M. \& Ochi, K. RNA polymerase mutation activates the production of a dormant antibiotic 3,3'-neotrehalosadiamine via an autoinduction mechanism in Bacillus subtilis. J. Biol. Chem. 279, 3885-3892 (2004).

18 Tanaka, Y., Tokukyama, S. \& Ochi, K. Activation of secondary metabolite-biosynthetic gene clusters by generating rsmG mutations in Streptomyces griseus. J. Antibiot. 62, 669-673 (2009).

19 Lautru, S., Deeth, R. J., Bailey, L. M. \& Challis, G. L. Discovery of a new peptide natural product by Streptomyces coelicolor genome mining. Nat. Chem. Biol. 1, 265-269 (2005).
20 Challis, G. L. \& Hopwood, D. A. Synergy and contingency as driving forces for the evolution of multiple secondary metabolite production by Streptomyces species. Proc. Natl Acad. Sci. USA 100, 14555-14561 (2003).

$21 \mathrm{Bibb}, \mathrm{M}$. The regulation of antibiotic production in Streptomyces coelicolor $\mathrm{A} 3(2)$. Microbiology 142, 1335-1344 (1996).

22 Rigali, S. et al. Feast or famine: the global regulator DasR links nutrient stress to antibiotic production by Streptomyces. EMBO Rep. 9, 670-675 (2008).

23 Carata, E. et al. Phenotypes and gene expression profiles of Saccharopolyspora erythraea rifampicin-resistant (rif) mutants affected in erythromycin production. Microb. Cell Fact. 8, 18 (2009).

24 Tala, A. et al. Activation of dormant bacterial genes by Nonomuraea sp. strain ATCC 39727 mutant-type RNA polymerase. J. Bacteriol. 191, 805-814 (2009).

Supplementary Information accompanies the paper on The Journal of Antibiotics website (http://www.nature.com/ja) 